\title{
LA VIOLENCIA DICTATORIAL Y LA VIOLENCIA ESTATAL DE LARGO PLAZO EN EL CONO SUR DE AMÉRICA LATINA: ENTRE LO EXCEPCIONAL Y LO HABITUAL
}

\author{
Dictatorial violence and long-term violence in the \\ Southern Cone of Latin America: between the exceptional \\ and the usual
}

\author{
Daniel Lvovich*
}

\begin{abstract}
RESUMEN
En este trabajo proponemos una serie de preguntas y vinculaciones entre las modalidades más generales de la violencia estatal contra las propias poblaciones, aplicadas en el largo plazo a lo largo del siglo XX en el cono sur latinoamericano, y las formas de violencia específicamente políticas desplegadas desde los estados en los períodos dictatoriales. Nuestra propuesta se inscribe en una línea de trabajo que ha reflexionado sobre los vínculos que los dispositivos de poder y represión utilizados por el estado terrorista durante los años dictatoriales tuvieron, con una serie de prácticas y relaciones sociales previamente existentes así como las desplegadas en los tiempos que la sucedieron.
\end{abstract}

Palabras clave: Violencia; Dictaduras; Cono Sur

\begin{abstract}
In this paper we propose a series of questions and relations between the most general modalities of state violence against the populations applied in the long term throughout the 20th century in the Latin American South Cone, and specifically political forms of violence deployed from the states in the dictatorial periods. Our proposal is part of a line of work that has reflected on the links that the devices of power and repression used by the terrorist state during the dictatorial years had, with a series
\end{abstract}

* Universidad Nacional de General Sarmiento/ CONICET. E-mail: dlvovich@ungs.edu.ar 
of practices and social relations previously existing as well as those deployed in the times that happened.

Keywords: Violence; Dictatorships; Southern Cone

Es posible sostener que las historiografías latinoamericanas de la historia reciente o del tiempo presente, como se ha dado en llamar en distintos países de la región, en sus esfuerzos por dar cuenta de las particularidades de las violencias de estado desplegadas por los regímenes dictatoriales instaurados en las décadas de 1960 y 1970, han tendido a considerar a estos períodos como excepcionales debido no solo a sus características institucionales sino, sobre todo, por el grado de violencia represiva dirigida contra los opositores políticos. En efecto, y pese a las diferencias entre los distintos casos nacionales, estos regímenes aplicaron formas extremas de violencia, en ocasiones contra sectores sociales antes no alcanzados por la represión estatal. Pero desde el punto de vista del análisis histórico, ello provocó que en general no se haya atendido con suficiente énfasis a los vínculos con otras formas y modalidades de violencia desplegados desde los estados, tanto antes como después de las dictaduras.

En este trabajo buscamos problematizar estas perspectiva, proponiendo en cambio una serie de preguntas y vinculaciones entre las modalidades más generales de la violencia estatal contra las propias poblaciones, aplicadas en el largo plazo a lo largo del siglo XX, y las formas de violencia específicamente políticas desplegadas desde los estados en los períodos dictatoriales. Nuestra propuesta se inscribe en una línea de trabajo que, para el caso argentino, ha reflexionado sobre los vínculos que los dispositivos de poder y represión utilizados por el estado terrorista durante los años dictatoriales tuvieron con una serie de prácticas y relaciones sociales previamente existentes (Tiscornia, 1977, Tiscornia y Sarrabayrouse, 2004, Calveiro, 1998), así como las desplegadas en los tiempos que la sucedieron. A su vez, es preciso articular estas manifestaciones específicas de violencia dentro del concepto mayor de violencia estructural, que se aplica a las en las que se produce un daño en la satisfacción de las necesidades humanas básicas como resultado de los procesos de estratificación social, es decir, sin necesidad de formas de violencia directa. El término violencia estructural remite a la existencia de 
un conflicto entre dos o más grupos de una sociedad y caracterizados en términos de clase, género, etnia, u otros en el que el acceso a los recursos es resuelto sistemáticamente a favor de alguna de las partes y en perjuicio de las demás, debido a los mecanismos de estratificación social. Este concepto permite pensar las firmas de violencia represivas como un mecanismo necesario para mantener una determinada estructura de poder cuando existen altos niveles de violencia estructural, como es habitual en los casos latinoamericanos. De igual modo la conflictividad social, ya organizada en torno a movimientos políticos y sociales o desestructurada - bajo la forma de delincuencia - se explican en buena medida como respuestas a la violencia estructural. (La Parra y Tortosa, 2003)

No proponemos con ello borrar la especificidad de la represión política ejercida desde los estados dictatoriales, sino intentar una reflexión acerca de los modos en que esta se articula necesariamente con las formas habituales de violencia institucional, dada la continuidad de la dominación social y del andamiaje institucional y represivo, incluyendo la legislación, el sistema judicial, las instituciones penitenciarias y las fuerzas policiales y militares. Buscamos con ellos también contribuir a precisar los perfiles de la represión específicamente política, y a entender las modalidades de estructuración de políticas de la memoria que privilegian determinadas víctimas de la represión estatal y no toman en cuenta otras.

\section{I}

En su conocido ensayo, Eduardo González Calleja recoge una serie de definiciones sobre el concepto de represión de diversos autores que se pueden aplicar en un sentido amplio. La represión fue definida “....como el empleo o la amenaza de coerción en grado variable, aplicada por los gobiernos sobre los opositores reales o potenciales con vistas a debilitar su resistencia frente a la voluntad de las autoridades", y como “...toda actividad institucional que tiende a cohibir los comportamientos colectivos". También, fue caracterizada como "...la acción de gobierno que discrimina brutalmente a personas o a organizaciones que se considera que 
presentan un desafío fundamental a las relaciones de poder existentes o las políticas clave del gobierno".

Asimismo, González Calleja propone que la represión puede ser entendida como “... una amenaza contra la integridad personal, y es desplegada por los gobiernos, pero también por organizaciones internacionales o por grupos profesionales" es decir, "por aquellas instituciones dotadas de autoridad legítima o de facto, y de medios coercitivos para hacer respetar esa autoridad como parte de un ordenamiento legal en vigor." Por último, la represión es entendida "como el conjunto de mecanismos dirigidos al control y la sanción de conductas desviadas en el orden ideológico, político, social o moral" y resulta un concepto muy cercano a la noción de violencia política. (González Calleja, 2006, sin paginar).

La represión no resulta idéntica a la violencia corporal. En palabras de González Calleja:

"Entendida como un principio universal de dominio, la coerción física no es necesaria para asegurar la conformidad de los miembros de una sociedad a las normas que la rigen, sino que es una condición para que la mayoría continúe voluntariamente desempeñando sus obligaciones bajo reglas legítimas que ellos mismos defienden. Por ello, en su grado de menor visibilidad, aparece vinculada con fenómenos como el control social y la violencia subliminal o "estructural". Como veremos más adelante, la represión engloba un amplio abanico de actuaciones, que pueden ir desde la eliminación física del disidente hasta el dirigismo de conductas públicas y privadas a través, por ejemplo, de la imposición de una cierta moral o de una cultura oficiales, en cuyo caso aparece como más cercana al control social, que puede ser definido como el conjunto de medios de intervención, positivos o negativos, que utiliza una sociedad o un grupo social para conformar a sus miembros a las normas que le caracterizan, impedir o desanimar los comportamientos desviados, y reconstruir las condiciones de consenso en caso de un cambio en el sistema normativo". 
Como se puede observar con claridad, a menos que se reduzca la noción de amenaza o desafío al orden a las formulaciones explícitamente políticas, no hay nada en estas nociones que impida pensarlas en un sentido restringido, y que las limite por tanto a las modalidades de represión estatal contra el enemigo político. La amenaza o desafío al orden puede ser percibida, de acuerdo a la configuración político - cultural de cada país y a las características de la conformación de su élite, como provenientes de grupos definidos en términos sociales - obreros, campesinos, movimientos sociales de distinto tipo - raciales o étnicos - como los pueblos originarios u otros grupos, - de género - el feminismo, los movimientos por la diversidad sexual u otros, además de los específicamente políticos.

Esto puede ser considerado de esa manera en una perspectiva general, pero puede aplicarse mucho más aun para los casos latinoamericanos. Ello se debe por un lado a la inestabilidad institucional de la región a lo largo del siglo XX, que provocó que sucesivas dictaduras hayan apelado de manera creciente y acumulativa a los métodos represivos dirigidos contra diferentes sectores de la sociedad, y no solamente contra los enemigos políticos. Así, la desposesión de campesinos, el endurecimiento de los ritmos y condiciones del trabajo industrial, la censura, la prohibición de huelgas o la expulsión de empleados públicos y profesores de sus trabajos fueron, de acuerdo a cada caso nacional, formas represivas habituales y reiteradas. Pero, por otro lado, la represión, política o social, no resulto una práctica reservada con exclusividad a los gobiernos dictatoriales. Baste enumerar los eventos de la Semana Trágica de 1919 o la represión en la Patagonia en 1921, bajo el gobierno de Hipólito Yrigoyen, la masacre de Napalpí en el Chaco en 1924, durante la gestión de Marcelo T. de Alvear - o las matanzas de Pilagá o de Rincón Bomba de 1947 - ya bajo el gobierno de Perón - en el Territorio Nacional de Formosa, en Argentina; las muertes de campesinos en conflictos por la tierra o la masacre de obreros de Ipatinga, en octubre de 1963, durante el mandato de João Goulart; o la matanza en la Escuela Santa María de Iquique, en el norte salitrero chileno, en 1907, bajo la administración de Pedro Montt. No proponemos aquí una discusión sobre la responsabilidad directa de los gobiernos nacionales en estas masacres, sino que buscamos señalar con estos ejemplos la inadecuación de la asimilación exclusiva entre dictaduras y represión a gran escala.

Pero si avanzamos un paso más, podemos considerar que, en particular en la segunda mitad del siglo XX y al calor de las perspectivas 
anticomunistas y de la Doctrina de la Seguridad Nacional, sucesivas medidas y estados de excepción jalonaron las diversas experiencias democráticas sudamericanas, incluidos los casos de los países con mayor estabilidad institucional de la región, como Uruguay y Chile (Iglesias, 2001; Franco e Iglesias, 2011 y 2015, Loveman, 2016). Para el caso chileno, Brian Loveman y Elizabeth Lira (2000) han estudiado el desarrollo de la violencia estatal ocurridos a lo largo de la historia del siglo XX, fenómeno ocluido de la memoria publica por "las cenizas del olvido", por olvidos deliberados que ocultaban la represión estatal a los movimientos sociales y fueron acompañados por amnistías para sus responsables

Desde estas perspectivas se aprecia cómo se agrava el carácter represivo del Estado en el Cono Sur a lo largo del siglo, revelando como la dicotomía democracia-dictadura, necesaria para dar cuenta de otros aspectos de la historia latinoamericana, se revela impotente para brindar un marco conceptual adecuado a estas dimensiones del proceso histórico.

De esta situación se puede señalar, como ha hecho Roberto Pittaluga para el caso argentino, que con el dominio cada vez más frecuente de la situación excepcional, en la cual la ley es directamente dejada a un lado, o la misma legalidad decide su puesta en suspenso, se aprecia cómo se agrava el carácter represivo del Estado, pero también cómo ese perfil marcadamente represivo tiene, como contracara, un lado productivo que se consolida en el mismo crescendo del proceso. "La ininterrumpida sucesión de hechos excepcionales fortalece esta deriva por la cual la excepción se convierte, velozmente, en la condición normal, es decir, se normaliza una situación de excepción.” (Pittaluga, 2008).

La excepcionalidad se formuló en algunas ocasiones como una suspensión efectiva por vía legal de algunos derechos ciudadanos, pero en otras - en lo atinente a los sectores más subalternos, para quienes la legalidad constitucional nunca constituyó una realidad que los protegiera de la opresión más directa - en una realidad efectiva más allá y al margen de toda expresión jurídica. Resulta más que adecuado recurrir aquí a la octava tesis de filosofía de la Historia de Walter Benjamin, que nos recuerda que 
"La tradición de los oprimidos nos enseña que el 'estado de excepción' en el cual vivimos es la regla.". ${ }^{1}$

¿De qué modo se vinculan entonces los medios represivos habituales del Estado con la específica represión política dictatorial? Señalemos para comenzar las características diferenciales de cada caso. Los regímenes dictatoriales que se implantaron en los países del Cono Sur de América Latina desde la década de 1960 se desarrollaron en un período que abarca un cuarto de siglo, y ejercieron su dominación sobre países con dimensiones, historias y estructuras sociales muy distintas. A la vez, las modalidades institucionales de los regímenes considerados fueron muy diferentes entre sí, a lo que se debe agregar la muy diversa evolución y transformaciones en el tiempo de cada uno de los casos considerados. En materia de aplicación de la violencia sobre los opositores, las cuatro dictaduras coincidieron en la coordinación represiva a través de la Operación Cóndor, un plan secreto que realizo tareas de inteligencia, secuestro y asesinatos de opositores, llevado a cabo por los organismos represivos de los cuatro países considerados más los de Bolivia y Paraguay. Las dictaduras argentina y chilena fueron, en ese orden las más sanguinarias desde la perspectiva de la aplicación de la violencia represiva. En el caso brasileño se registraron extendidas prácticas de censura, propaganda y guerra psicológica, así como encarcelamientos masivos y una muy extendida práctica de la tortura, pero el asesinato de los enemigos políticos fue cuantitativa y porcentualmente muy bajo en comparación con sus vecinos. En Uruguay se desarrolló una alta capacidad de control de la población civil, combinado con una represión gradual y altamente selectiva. De hecho, de los 230 uruguayos desaparecidos, 150 fueron

${ }^{1}$ Consideramos preciso conservar la percepción benjaminiana acerca del carácter diferencial de la excepcionalidad, que consideramos en cierta medida se diluye en la reflexión de Agamben acerca del estado de excepción como forma permanente del gobierno en el siglo XX. (Agamben, 2005) 
secuestrados en Argentina. La prisión política de larga duración fue un instrumento muy usado por la dictadura uruguaya. En Chile la represión inmediata tras el golpe fue muy amplia, primando las detenciones y ejecuciones sumarias, con un uso más limitado de la desaparición forzada. Esta inicial visibilidad de la represión, se articuló en los años sucesivos con una progresiva extensión de la violencia clandestina. La clandestinidad de la represión, la primacía del método de desaparición de personas y un número muy superior de desaparecidos respecto a sus vecinos caracterizan al caso argentino tanto como la sustracción de los hijos pequeños de las mujeres secuestradas o asesinadas. (Alonso, 2013: Lvovich, 2019)

Pero más allá de estas especificidades, es necesario plantear los modos en que otras modalidades de violencia se vinculan con la represión específicamente política. Se podría para ello postular explicaciones muy genéricas, acerca de los modos en que la extremada desigualdad social, la deshumanización propia del racismo, los modos de demonización de un parte de la población por el anticomunismo, la exclusión propuesta por las culturas políticas autoritarias, entre otros factores, conectan en grandes trazos las diversas manifestaciones de violencia represiva que afectaron a los países del Cono Sur a lo largo del siglo XX. ${ }^{2}$

Algunos textos nos brindan claves importantes para pensar estos problemas en tanto tecnologías de poder, como dispositivos represivos disponibles con anterioridad que en momentos determinados se ponen al servicio de la violencia específicamente destinada a controlar y castigar al enemigo político.

La reflexión de Pilar Calveiro (1998) para el caso argentino ofrece valiosos elementos para pensar este problema. En su análisis de las reiteradas intervenciones militares en la vida política argentina, la autora señala que para asumir el disciplinamiento de la sociedad, ellas mismas habían disciplinado su cuerpo "de manera tan brutal como para internalizar, hacer carne, aquello que imprimirían sobre la sociedad." Desde principios del siglo XX, bajo el presupuesto del orden militar se impuso el castigo físico, una modalidad de la tortura, sobre militares y conscriptos, es decir

\footnotetext{
${ }^{2}$ Tal como propone Enzo Traverso, no se trata de la búsqueda de causas ni la recaída en el mito de los orígenes, sino de captar los elementos en el contexto que se inscribe el fenómeno, de manera de reconstruirlo retrospectivamente (Traverso, 2003, pp.25-26)
} 
sobre toda la población masculina del país. "Cada soldado, cada cabo, cada oficial, en su proceso de asimilación y entrenamiento aprendió la prepotencia y la arbitrariedad del poder sobre su propio cuerpo y dentro del cuerpo colectivo de la institución armada". (Calveiro, 1998, pp. 5 y 6) De modo que, en estas condiciones, no resulta extraño que el castigo físico se convirtiera en un medio habitual de imposición del poder dictatorial sobre los prisioneros políticos de las dictaduras. Más aun, Calveiro nos recuerda que "la tortura adoptó una modalidad sistemática e institucional en este siglo, después de la Revolución del 30 para los prisioneros políticos, y fue una práctica constante e incluso socialmente aceptada como normal en relación con los llamados delincuentes comunes. (Calveiro, 1998, 14).

Evidentemente, y como señala la autora, el poder desaparecedor de la dictadura argentina supone un elemento rupturista y novedoso cuya explicación no se agota en los antecedentes de los métodos represivos, pero estos son imprescindibles en cuanto factores que ayudan a su comprensión. "Sin embargo, cabe señalar también que las características de este poder desaparecedor no eran flamantes, no constituyeron un invento. Arraigaban profundamente en la sociedad desde el siglo XIX, favoreciendo la desaparición de lo disfuncional, de lo incómodo, de lo conflictivo" Calveiro, 1998, 15) No obstante, la dictadura instaurada en 1976 tampoco puede entenderse como una simple continuación o una repetición aumentada de las prácticas antes vigentes. "Representó, por el contrario, una nueva configuración, imprescindible para la institucionalización que le siguió y que hoy rige. Ni más de lo mismo, ni un monstruo que la sociedad engendró de manera incomprensible."

Por su lado, Carla Villalta (2012) analizó las formas en que las prácticas de sustracción de niños, llevadas a cabo durante la última dictadura militar argentina - algunas de las cuales devinieron en adopciones - no sólo fue desarrollada clandestinamente, sino que también apeló a formas pseudo-legales en el ámbito judicial. Esto no se debió solamente al mayor o menor grado de afinidad político-ideológica de algunos de los integrantes del Poder Judicial con la dictadura militar, sino también a las características de prácticas, relaciones y rutinas burocráticas presentes en él desde tiempo atrás, incluyendo tanto las amplias atribuciones de los magistrados para decidir sobre el futuro de los niños, como su marcada impronta clasista. Así, métodos, canales, procedimientos y criterios usados con anterioridad para la entrega de niños huérfanos o institucionalizados se emplearon para la entrega de hijos de desaparecidos 
en los años dictatoriales. De tal modo, se propone una explicación de la apropiación criminal de niños ocurrida durante la última dictadura militar apelando a un análisis que se inicia en 1870 para dar cuenta de prácticas sociales hondamente arraigadas sobre un sector de la infancia pobre y sus familias.

A su vez, las instituciones policiales especializadas en la represión política preceden en mucho a la etapa dictatorial. En Brasil, las primeras secciones de la policía política fueron creadas inicialmente en Río de Janeiro - por entonces capital de la República - en 1922, en San Pablo en 1924 y en Minas Geraes en 1927. Aunque surgieron con distintos nombres, "com o tempo, se cristalizou uma denominação que viraria sinônimo de repressão, Delegacias ou Departamentos de Ordem Política e Social (DOPS)." (MOTTA, 2009, 6). En Chile, desde fines de la década de 1930 asistimos a "la militarización del conflicto social, esto es, la reincorporación de las fuerzas armadas a tareas de orden interno". La militarización política se refiere a la intervención de los militares en el debate y la acción política, irrumpiendo en ámbitos propiamente civiles, proceso por el cual los valores, la ideología y los patrones de conducta militares influyen en los asuntos políticos, sociales, económicos e internacionales. (Valdivia, 2019, s/p). También en Chile, la Ley 7200, de 21 de julio de 1942 otorgó facultades extraordinarias al Presidente Juan Antonio Ríos y en su artículo 23 lo autorizó para declarar "Zona de Emergencia" partes del territorio nacional en caso de peligro de invasión o ataque exterior, pero también ante sabotajes contra la seguridad nacional. Sin embargo, a lo largo del siglo los gobiernos usaron las zonas de emergencia para controlar al movimiento obrero y a la izquierda, conllevando el “...control de la libertad de expresión y prensa, de opinión, de movimiento y de actividad política de los trabajadores." (Valdivia, 2019)

Como vemos entonces, muchos de los dispositivos empleados en los años dictatoriales tienen una muy larga historia y fueron creados en algunos casos para intervenir en áreas de la vida social no vinculados de manera directa a la represión política. Dar cuenta de estas articulaciones no supone desconocer la especificidad de los métodos dictatoriales, sino sencillamente presentar algunos elementos específicos que permiten insertar sus métodos represivos en una genealogía de largo plazo. 


\section{III}

Si podemos advertir la existencia de dispositivos y mecanismos de larga duración, que disponibles en determinados campos se trasladan a la represión específicamente política, podemos observar también la existencia en el mediano plazo de violencias tan persistentes como invisibles.

En el informe de la Comisión de la Verdad de Brasil esto queda patentemente expresado en relación al campesinado, sometido a expropiación y a represión antes y durante la dictadura militar

. "O mesmo se repetiu na prelazia de São Félix, em Mato Grosso, sob responsabilidade de dom Pedro Casaldáliga.Mas o Estado também reprimiu os trabalhadores rurais que lutaram por direitos trabalhistas recém-conquistados desde a Constituição de 1945, sempre no sentido de favorecer as práticas arcaicas - mesmo quando inconstitucionais - dos grandes proprietários de terra. Da mesma forma, o Estado brasi-leiro esteve quase sempre ao lado dos grandes invasores de terras e dos beneficiários de fraudes cartoriais - fossem empresas, fossem famílias tradicionais - contra os posseiros que tiravam delas sua sobrevivência. Governos estaduais e prefeituras, o exército e a polícia, o governo federal e o sistema Judiciário viraram sistematicamente as costas para as necessidades do trabalhador rural e para a luta dos pequenos agriculto-res no sentido de conservar o direito de cultivar um pedaço de terra. As terras do interior do Brasil eram consideradas sem dono, a contrapelo da lei e à revelia das populações que viviam nelas e as cultivavam. Ainda que as alianças que sustentaram o projeto de ocupação do interior do país durante o governo Vargas (a chamada "marcha para o Oeste", voltada para a ocupação das terras de Mato Grosso e Goiás) não coincidissem exatamente com as dos grupos envolvidos no projeto de "integração nacional" dos governos Médici e Geisel, em ambos os casos as terras do Brasil foram distribuídas entre empresários interessados em tocar empresas agropecuárias ou projetos extrativistas como se ali não existissem moradores - o que vale tanto para os camponeses quanto para os povos indígenas." 2014, tomo 2, 94

Una larguísima tradición que hunde sus raíces en el período colonial pero que se reaviva en el siglo XX, ha naturalizado en el Brasil anterior a 1964 la expropiación, el sojuzgamiento y el asesinato de campesinos e indígenas, por acción estatal o por permitir y favorecer los crímenes de los grandes propietarios territoriales del interior del país. Por 
ello, no es sorprendente que, en el caso de los trabajadores rurales paulistas no alcanzados- antes o después de 1964 - por la legislación trabalhista ni por el movimiento sindical, el golpe militar no haya significado un marco de referencia decisivo. (Martinez - Allier y Boto, 1978, 247)

Ludmila de Silva Catela (2010) explica que la historia en la región del noroeste de Argentina, arrastra una tensa relación entre los pobladores campesinos, indígenas y obreros, frente a patrones y empresas, relación que ha sido de constante sometimiento, enfrentamientos y represiones. Una de las características específicas fue la dependencia y subordinación de las fuerzas represivas (policía y gendarmería) a los intereses de las elites económicas y políticas locales. Así, ingenios azucareros y minas usaron y usan a estas fuerzas del Estado, como un brazo más de sus empresas, generando una perversa simbiosis entre el poder político y las elites económicas.. En ese contexto de largo plazo, la dictadura militar no significò en absoluto un corte tajante. La discursividad campesina y la expresiones que emplean estos sectores expresa un tipo de violencia que no se inició en 1976 ni terminó en 1983.. Las nociones más generales sobre la violencia sufrida por los campesinos y obreros dela región dan cuenta de unas memorias largas de la represión, que expresan unas violencias ejercidas de manera regular y por décadas por las elites económicas y políticas locales aunadas con el aparato represivo del Estado. No hay por tanto en las narraciones sobre las desapariciones en el caso estudiado Tumbaya, Jujuy - una discontinuidad radical en relación a otros períodos.

Para el caso chileno, dando cuenta de procesos de algún modo comparables, Sebastian Leiva ha constatado que los trabajos académicos que abordaron la represión que se desató en los primeros momentos del golpe de 1973 contra los enemigos políticos del régimen, han obviado sorprendentemente la represión que se desató simultáneamente contra los delincuentes comunes, que si bien no fue tan cruel y sistemática como en los casos citados, en algunas poblaciones de la capital estuvo cerca de asimilársele en magnitud y efecto (Leiva, 2010, 288). En la población La Legua y sus barrios la "razzia anti delincuentes" cobró mayor cantidad de víctimas., dado que en aquel sector se produjo la muerte de 32 personas con antecedentes delictuales, sobrepasando ampliamente a las 17 víctimas de esa zona asociadas a organizaciones políticas, a lo largo de la dictadura militar. Situaciones similares ocurrieron en otros barrios populares de la capital chilena. Leiva afirma, por lo tanto, en base a información de prensa, de los informes Rettig y de la Corporación Nacional de Reparación y 
Reconciliación, que la represión estatal tras el golpe militar del 11 de septiembre no se concentró única y exclusivamente en los militantes de los partidos de izquierda y en los activistas de las organizaciones sociales populares, sobre los que se concentró la atención a la hora de dar cuenta de la violación a los derechos humanos por parte de la dictadura. Más aún. El informe de la Corporación de Reparación y Reconciliación chilena (1996) señala que de los 247 casos de "ejecución al margen del debido proceso" acontecidos entre el 11 de septiembre de 1973 y el 31 de marzo de 1974, "en no menos" de 190 casos se trataba de víctimas con "antecedentes policiales de delincuencia común, de ebriedad habitual, de reyertas conyugales, familiares o vecinales y de vagancia". "Se aprecia que más de la mitad de los asesinados tenía la condición a la que hemos referido (asesinados en grupos, arrestados a la vista de sus vecinos, identificados como delincuentes y literalmente amontonados en diversos lugares de Santiago), pero eran prácticamente invisibles.” (Leiva, 2010, 300)

La represión a los activistas de izquierda se explica por el interés de la dictadura de desarticular a los partidos y organizaciones populares para anular su capacidad de resistencia, y el discurso antimarxista resultó central en la retórica del régimen. Sin embargo, a esa orientación predominante se fue sumando un discurso, y sobre todo una práctica anti delincuencial, la cual se expresó claramente en la actuación de aquellos organismos del Estado vinculados al control de los "antisociales". Por ello, Leiva plantea que la dictadura militar "...vio en los delincuentes comunes, y más ampliamente en los "antisociales" - homosexuales, ebrios, "malos" esposos y vecinos -, un segmento social a reprimir y controlar, en función de avanzar en el reordenamiento de una sociedad que, según sus planteamientos, en los tiempos de la Unidad Popular había terminado por romper todos sus controles" (Leiva, 2010, 299-300). La prensa de la época justificó, cuando no promovió, la represión contra los militantes de izquierda y sujetos sociales "disfuncionales" como los delincuentes, representando a ambos grupos como un peligro para el orden social. Leiva propone como explicación que el rechazo social hacia los delincuentes llevo a promover o al menos a ignorar la represión que se desató sobre ellos, en un silencio que abarca a los partidos y activistas de izquierda que han denunciado violaciones a los derechos humanos. A propósito de estos grupos, los propios marcos ideológicos e incluso éticos de la izquierda la llevan a rechazar a los delincuentes en vida y a ignorarlos en la muerte. El conjunto de este proceso resulta imposible de comprender al margen de un 
análisis en una escala temporal amplia que dé cuenta de los modos en que distintos sectores de la sociedad chilena se vincularon con los elementos considerados antisociales. ${ }^{3}$

La perduración de estas y muchas otras violencias de largo plazo y exclusiones ancestrales, sostenidas a la vez en perspectivas racistas y clasistas de larguísima duración, nos permite pensar en que para determinadas - y amplias - franjas de la población de nuestros países, las dictaduras no constituyeron de ningún modo una ruptura fundamental, sino una profundización de tendencias seculares. Las memorias largas de estas poblaciones - con la excepción, en nuestro caso, de los familiares de los delincuentes comunes asesinados en Chile en 1973 - no integran de modo decisivo las dictaduras en sus registros. A la vez, se trata de sectores sociales cuya victimización es muchas veces invisibilizada, aun en el seno de las narrativas humanitarias que no logran articular en las perspectivas metropolitanas estas perspectivas de largo plazo. Se trata, en definitiva, de aquellos grupos - subalternos, sumergidos, victimizados - para quienes la excepción no deja nunca de convertirse en la regla.

IV

¿Se trata de historia pasada? ¿Podemos tranquilizarnos considerando que hemos superado estas situaciones?

Como en otros ordenes de la vida social, las promesas de la democracia lejos estuvieron de concretarse, en primer lugar, por “...la coexistencia de procesos polarizantes que aumentaron la desigualdad social

\footnotetext{
${ }^{3}$ Sin ir más lejos, está el asesinato de homosexuales durante el primer gobierno de Carlos Ibáñez del Campo (1927-1931), tema aún en la categoría de "mito", la expulsión de ebrios y familias de mal vivir en las tomas de terrenos urbanos dirigidas por organizaciones de izquierda en las décadas de 1960 y 1970 (sino antes), la erradicación masiva de asentamientos precarios (teóricamente con muchos ladrones y gente de mal vivir) y la ejecución, como hemos visto, de decenas de delincuentes comunes en los primeros meses del régimen militar, y la creciente exigencia, en la actualidad, de castigar con todo el rigor posible a los delincuentes. Todo ello da cuenta de las variadas manifestaciones de una complejísima relación que, en ciertas coyunturas, lleva a la sociedad a defender sus normas, costumbres y propiedades a costa de la vida de quienes las ignoran. (Leiva, 2010, 331)
} 
y profundizaron situaciones de desprotecciones sociales, provocando el desencanto con las instituciones políticas y jurídicas." (Scarponetti, 2019, 169) Como ha sido señalado, “ ...la (in)efectividad de la ley y la exclusión en América Latina (Méndez, O'Donnell y Pinheiro, 2002) trataba de un fenómeno del cual se podían reconocer tramadas y múltiples fuentes que amenazaban su realización" entre ellas la continuidad de las violencias institucionales, de diversas manifestaciones de vulnerabilidad de derechos y de reformas institucionales ineficientes para el acceso a la justicia. La tendencia hacia la criminalización de sectores populares hacia la judicialización creciente de conflictos parece acentuarse en la región, al tiempo que el aumento de muchos indicadores delictivos provocó que las administraciones de justicia - cuyo habitual conservadurismo rara vez se modifica - se orientaran hacia un giro punitivo y autoritario. La violencia estructural, de ese modo, no se ha dejado de manifestar, en algunos casos, con creciente importancia.

No presentaremos aquí un análisis exhaustivo de esas violencias represivas en democracia, pero si algunos ejemplos y casos contundentes.

En los países del cono sur la violencia policial se convirtió en un dato recurrente. En Argentina ha sido considerada un accionar institucional de violación sistemática de los derechos humanos, en particular de los derechos de los jóvenes de sectores populares (Pereyra, 2015). En las décadas de los ochenta y noventa, mientras continuaba su trabajo de denuncia y búsqueda de justicia por los crímenes cometidos durante la dictadura, algunos organismos de derechos humanos comenzaron a trabajar sobre las violaciones de derechos fundamentales que ocurrían en ese tiempo, articulados con equipos académicos, al tiempo que se creaba un incipiente movimiento de víctimas de hechos de violencia policial. "La violencia institucional fue ganando fuerza como una categoría política capaz de señalar algunos de los patrones estructurales de violaciones de derechos humanos en democracia" (Perelman y Tufro, 2017, 4). Esta conceptualización implicaba dar cuenta de la responsabilidad estatal "pero construyendo modos de sistematicidad que no señalaban la existencia de un plan centralizado, sino de prácticas, rutinas, normas, problemas de diseño institucional y otras condiciones necesarias para la reiteración de diferentes 
tipos de violaciones de los derechos humanos." (Perelman y Tufro, 2017, $4)^{4}$

La Coordinadora contra la Represión Policial e Institucional (CORREPI), y el Centro de Estudios Legales y Sociales (CELS) sistematizan desde hace años información al respecto, y los datos resultan aterradores. Desde 1996 el CELS registra en una base de datos los hechos de violencia en los que participaron funcionarios de agencias estatales y privadas de seguridad y las víctimas de esos hechos. Los hechos comprenden una tipología amplia, que no es judicial, sino que se desprende de la información que consignan los medios de comunicación en las notas: muertes en enfrentamiento, bajo custodia policial, por represión durante una protesta social, ejecución, negligencia funcional, uso particular de la fuerza, durante un operativo tipo razzia o por el ejercicio de la violencia en las cárceles. El acumulado entre 1996 y 2018 solo para el área metropolitana de Buenos Aires es de 3,508 asesinados. $^{5}$ La misma institución ha contabilizado en todo el país 727 muertos en protestas sociales desde 1995, a manos de agentes estatales. ${ }^{6}$

Por su parte, la CORREPI desarrollo un archivo nacional de personas que murieron como consecuencia directa o indirecta de la necesidad intrínseca de los gobiernos de reprimir. ${ }^{7}$ El período relevado va desde 1983 hasta febrero de 2019 y - aunque la información para los

\footnotetext{
${ }^{4}$ Las formas de violencia institucional atraviesan a prácticamente todas las dimensiones del trabajo policial con el delito: desde la supuesta prevención a través del "olfato policial" hasta la represión haciendo uso abusivo e ilegal de la fuerza, pasando por la investigación con métodos ilegales y la connivencia con negocios delictivos. El desempeño muchas veces cómplice o negligente del Poder Judicial ha sido considerado en sí mismo una forma de violencia institucional y es condición de posibilidad para la persistencia de patrones de violencia policial o penitenciaria. (Perelman y Tufro, 2017, 7)

${ }^{5}$ https://www.cels.org.ar/web/letalidad-policial-estadisticas/

${ }^{6}$ https://www.cels.org.ar/protestasocial/

${ }^{7}$ Las modalidades desagregadas son gatillo fácil (fusilamientos); muertes de personas detenidas (que en buena medida corresponden a la aplicación de tormentos, e incluyen, también, algunos casos de desapariciones); fusilamientos en movilizaciones u otras protestas (es decir, los asesinatos cometidos en el marco de la represión a la protesta y el conflicto social); muertes intrafuerza o intrafamiliares (casos en que el autor utiliza, para "resolver" un conflicto interno o familiar, los recursos represivos que le provee el estado); causas fraguadas, o consecuencia de otros delitos y otras circunstancias (que incluye la mayoría de las desapariciones)
} 
primeros quince años resulta muy incompleta . la cantidad de víctimas mortales relevadas alcanza las 6.564 personas asesinadas en democracia. ${ }^{8}$

En relación a Chile, el Comité de Derechos Humanos de Naciones Unidas, en 2007, conminó a ese estado a "tomar medidas inmediatas y eficaces para poner fin a esos abusos, vigilar, investigar y cuando proceda, enjuiciar y sancionar a los funcionarios de la policía que cometan actos de malos tratos en contra de grupos vulnerables". El mismo estudio daba cuenta de que la violencia policial había sido analizada en Chile a propósito de contextos específicos, como la protesta social y el conflicto del Estado chileno con el pueblo mapuche en la Araucanía, e indicaba que uno de los contextos en que el fenómeno era recurrente era el de "las poblaciones verdaderamente sitiadas por la policía militarizada" (Vial Solar, 2017, 292). El Estado de Chile, en su último informe periódico dirigido al Comité contra la Tortura de las Naciones Unidas, reportó 802 casos de presunto uso excesivo de la fuerza por parte de policías entre 2010 y $2017 .{ }^{9}$

Asimismo, el Comité de Derechos del Niño de la ONU denunció en 2018graves vulneraciones a los derechos humanos de menores de edad, en un informe en el que señala la responsabilidad del Estado por la existencia de "graves violaciones de la convención internacional sobre los derechos del niño". El texto señala que existieron "graves negligencias por parte del personal responsable del cuidado de los menores" así como casos de "abuso sexual, torturas y tratos crueles e inhumanos" en residencias del Servicio nacional de Menores. ${ }^{10}$ A ello se suma, entre otros muchos elementos, que en cada conmemoración del golpe militar del 11 de septiembre o masiva movilización social, la respuesta ha sido el uso de una intensa fuerza policial, a la que se instruye en técnicas anti-guerrilleras, que provoca muertos y numerosos heridos.

Según un informe del Consejo Indígena Misionero (CIMI), vinculado a la Conferencia Nacional de Obispos de Brasil de 2017, al menos 1071 indígenas fueron asesinados en las últimas tres décadas,

\footnotetext{
${ }^{8}$ http://www.correpi.org/2019/archivo-2018-cada-21-horas-el-estado-asesina-a-una-persona

${ }^{9}$ https://radio.uchile.cl/2018/09/19/chile-reporta-a-la-onu-mas-de-800-casos-de-violencia-policial/.

${ }^{10} \mathrm{https}$ ://www.eldesconcierto.cl/2018/07/31/onu-denuncia-a-chile-por-las-violaciones-a-los-derechoshumanos-en-centros-del-sename/.
} 
proceso que se ha incrementado con la deforestación y apropiación de tierras para dar paso a la minería, y la agricultura industrial. El informe señala asimismo que 702 niños indígenas fallecieron en 2017 por causas vinculadas a la miseria y el abandono estatal, y que en el mismo año se registraron 128 suicidios entre los pueblos indígenas. Sólo en el estado de Mato Grosso do Sul se registraron 813 suicidios entre 2000 y 2017 (CIMI, 2018). En su informe Cartografiado CACI, el CIMI no duda en señalar que existe un verdadero genocidio en desarrollo en el estado de Mato Grosso do Sul. ${ }^{11}$

El Obispo Roque Paloschi, Presidente del Conselho Indigenista Missionário ha sostenido que el "Estado brasileiro tem se constituído, através de seus governantes, em principal promotor e mantenedor das violências contra os povos indígenas. A negligência premedi-ada dos que vivem dentro dos poderes públicos, por ações e omissões, são as sementes nefastas geradoras da morte e da miséria daqueles que clamam por Justiça em nosso país." (CIMI; 2018)

De este modo - y solo empleando estas estremecedoras informaciones, a la que podríamos en cada caso agregar muchas más, resultan evidentes las continuidades de la violencia estatal - o autorizada por los estados por sus omisiones - mientras otras áreas de la sociedad se encuentran protegidas por la legalidad propia del estado de derecho. Si en democracia se cometen crímenes de brutalidad policial en números altísimos y aún procesos genocidas, es inevitable pensar en las continuidades - institucionales, de personal burocrático y represivo, ideológicas, políticas, culturales - que articulan estas prácticas con sus precedentes dictatoriales, pero que hunden sus raíces en perspectivas y dispositivos que preceden en mucho a los regímenes dictatoriales de la segunda mitad del siglo XX.

\section{V}

\footnotetext{
${ }^{11}$ http://caci.cimi.org.br/\#!/dossie/968/?loc=-22.15052364379287,-54.75414276123047,11\&init=true.
} 
¿Significa lo que hemos reseñado hasta aquí que solo nos resta contar la historia, a la manera que Faulkner y antes que el Shakespeare propusieron, como "el relato de un loco, lleno de sonido y de furia, y que no significa nada"? ¿O que podríamos reducir nuestra narración a la de una simple cadena de violencias ininterrumpidas sobre los sectores subalternos, provocadas por el Estado, el capitalismo, el poder latifundista, la violencia colonial?

Aunque estos sean marcos generales e ineludibles para la comprensión de la violencia, una visión histórica de largo plazo debe poder generalizar, pero también diferenciar. Existe una violencia estatal de largo plazo - de la que contamos con más informaciones cuantitativas para los períodos post dictatoriales que para los que precedieron a los golpes militares - que, con ciertas variaciones, no deja de dirigirse contra las poblaciones subalternas, básicamente contra los campesinos, indígenas y pobres urbanos. Y existió en las dictaduras latinoamericanas - y esporádicamente también en períodos democráticos - una represión específicamente política, que debe entenderse en esos términos.

En algunos casos los datos cuantitativos de la represión política resultan relativamente bajos si los comparamos con los de la violencia social. Así, en Brasil se contabilizan 434 muertos y desaparecidos políticos entre 1946 y 1988 (CNV, 2014, Vol 3, p. 26) y para el mismo período se estima una cifra de al menos 8.350 indígenas asesinados por acción u omisión estatal, (CNV, 2014 Vol. 2, p. 205). Pero no se trata de realizar una comparación cuantitativa que minimizaría a un colectivo de víctimas, sino de comprender la naturaleza de los crímenes. Eliminación del enemigo político como acción concertada y sistemática de todas las fuerzas estatales en un caso, eliminación y subordinación de los sectores subalternos a través de políticas de una parte del estado que a menudo contrasta con acciones en sentido contrario de otras agencias de ese mismo estado en el otro.

Por ello, la operación historiográfica adecuada parece ser comprender la especificidad de la violencia dictatorial contra el adversario político en el marco de las formas más generales de la represión estatal, y analizar los tiempos cortos o medios de las experiencias dictatoriales en el marco de las violencias de largo plazo, sus agentes y sus dispositivos. Articular resulta así una operación esencial para diferenciar y comprender, aun considerando que es imposible dar cuenta de este conjunto si no es refiriéndolo a su vez a la violencia estructural de nuestras sociedades. 
Un segundo nivel de análisis es el relativo a las políticas de la memoria y sus omisiones. No podríamos decir que la memoria de la victimización de los sectores subalternos haya sido borrada. De hecho, hemos apelado en este mismo trabajo a distintas fuentes que dan cuenta de la represión contra campesinos, delincuentes comunes, indígenas o pobres urbanos.

Sin embargo, su lugar en las políticas conmemorativas resulta mucho menos visible y relevante que el de las víctimas específicamente políticas de las violencias dictatoriales. Muchos factores explican estas circunstancias. En primer lugar, esta relativa invisibilidad se motiva en el carácter subalterno de las víctimas, que limita fuertemente su capacidad autónoma para logar ubicar sus reclamos de justicia y de memoria en las esferas públicas nacionales. Como señalaba Paul Ricouer, "Se utiliza aquí una forma ladina de olvido, que consiste en desposeer a los actores sociales de su poder originario de narrarse a si mismos." Este desposeimiento va acompañado de una complicidad "que hace del olvido un comportamiento semipasivo y semiactivo, como sucede en el olvido de elusión, expresión de la mala fe, y su estrategia de evasión y esquivez motivada por la oscura voluntad de no informarse, de no investigar sobre el mal cometido por el entorno del ciudadano, en una palabra, por un querer-no-saber." (Ricouer, 2004, 572)

De modo que la ausencia de lo que podríamos llamar "poder conmemorativo" se complementa con la voluntad de amplios contingentes sociales de no saber, o de limitar la violencia estatal a un pasado que se considera definitivamente superado.

Nuestras sociedades de fines del siglo XX y comienzos del XXI han hecho un culto de la memoria de sus muertos, de sus mártires, de sus víctimas, y proliferan las instituciones de la memoria - los museos, los archivos específicos, los monumentos y, los ritos conmemorativos - pero a la vez las diferencias de poder simbólico se reproducen en el largo plazo con las capacidades diferenciales para incidir en los modos y objetos de la rememoración.

En ocasiones - tal como el caso de los delincuentes comunes analizados por Leiva - el estigma impidió a los familiares desplegar reclamos judiciales, demandas de reconocimiento y políticas de memoria, y aun operó impidiendo que el movimiento de Derechos Humanos incorporara estos casos a sus narraciones. 
Por último, la narración de las opresiones de largo plazo no se amolda a la temporalidad centrada en las dictaduras militares. Experimentadas secularmente, como un estado de excepción convertido en regla, se trata de memorias en las que las dictaduras no implican una discontinuidad radical respecto a otros períodos sino a lo sumo una intensificación de la violencia que tradicionalmente recibieron por parte las elites y las fuerzas policiales y militares. Esas experiencias no se remiten, por tanto, a pasados más o menos remotos, sino que se expresan como una continuidad que llega, como hemos visto, hasta nuestros días.

Pensar, por tanto, los modos en que integrar en las políticas de memoria estas experiencias diversas y estas temporalidades diferenciales resulta un desafío al que nuestras historiografías tienen la posibilidad de realizar sus aportes específicos.

\section{Bibliografía citada}

AGAMBEN, Giorgio, Estado de excepción, Buenos Aires, Adriana Hidalgo, 2005

ALONSO, Luciano, "Dictaduras regresivas y represiones en Iberoamerica: Trayectorias particulares y posibilidades de comparación" en: ALONSO, Luciano y AGUILA, Gabriela, (comps), Procesos represivos y actitudes sociales. Entre la España Franquista y las dictaduras del Cono Sur, Buenos Aires, Prometeo, 2013, pp. 43-68.

CALVEIRO, Pilar, Poder y desaparición. Los campos de concentración en la Argentina, Buenos Aires, Colihue, 1998.

COMISSÃO NACIONAL DA VERDADE (CNV), Brasil .Relatório: textos temáticos, Vol 2 y Vol3. Mortos y desaparecidos políticos, Brasília: CNV, 2014.

CONSELHO INDIGENISTA MISSIONÁRIO (CIMI)m Violência contra os Povos Indígenas no Brasil, Relatorio 2017, 2018 https://cimi.org.br/wpcontent/uploads/2018/09/Relatorio-violencia-contra-povos-indigenas_2017-

Cimi.pdf,

DA SILVA CATELA, Ludmila, "Pasados en conflicto. De memorias dominantes, subterráneas y denegadas” en: BOHOSLAVSKY, Ernesto, FRANCO , Marina, 
IGLESIASA, Mariana y LVOVICH, Daniel, Problemas de historia reciente del Cono Sur, Buenos Aires, UNGS - UNSAM, 2010, tomo 1, pp. 99-124

IGLESIAS, Mariana, "La excepción como práctica de gobierno en Uruguay, 19461963”, Contemporánea: historia y problemas del siglo XX, Montevideo, Vol. 2 , $\mathrm{N}_{-}^{\mathrm{o}}$. 2, 2011,pp. 137-155.

FRANCO, Marina e IGLESIAS, Mariana, El estado de excepción en Uruguay y Argentina. Reflexiones teóricas, históricas e historiográficas, Revista de História Comparada, Rio de Janeiro, v. 5, n. 1, 2011, pp.91-15.

FRANCO, Marina e IGLESIAS, Mariana ," El estado de excepción a escala comparada. Notas a partir de los casos argentino, chileno y uruguayo durante la década de 1950", Quinto Sol, Santa Rosa, La Pampa, Vol. 19, N 1, 2015, pp.1-23

GONZÁLEZ CALLEJA, Eduardo, “Sobre el concepto de represión”. Hispania nova. Revista de Historia Contemporánea, $N^{o}$ 6, 2006. http://hispanianova.rediris.es/6/dossier/6d022.pdf, consultado el 29/5/2019

LA PARRA, Daniel y TORTOSA, José María, "Violencia estructural: Una ilustración del concepto", Documentación Social ,131, 2003, pp. 57-72

LEIVA, Sebastián, "La represión que no importó. La violencia estatal contra los delincuentes comunes tras el golpe de Estado de 1973 en Chile" en: BOHOSLAVSKY, Ernesto, FRANCO, Marina, IGLESIAS, Mariana y LVOVICH, Daniel, Problemas de historia reciente del Cono Sur, Buenos Aires, UNGS - UNSAM, 2010, tomo 1, pp. 287- 302.

LOVEMAN, Brian, "The Political Architecture of Dictatorship: Chile before september 11, 1973”, Radical History, No.1224, 2016, pp. 11-41,

LOVEMAN, Brian y LIRA, Elizabeth; Las ardientes cenizas del olvido. Vía chilena de reconciliación política, 1932-1994, Lom, 2000.

LVOVICH, Daniel, "Authoritarianism, nationalism, fascism and National Security Doctrine. The debate on Latin American Southern Cone dictatorships", SAZ, Ismael, BOX, Zira, MORANT, Toni and SANZ, Julián (eds.), Reactionary Nationalists, Fascists and Dictatorships in the Twentieth Century: Against Democracy. ,Londres, Palgrave, 2019, pp. 327-343

MARTÍNES-ALIER, Verena y BOTO Jr, Armando (1978), “1974: Enxada e voto" en: CARDOSO, Fernando Enrique y LAMOUNIER, Bolivar, Os partidos e as eleiccoes no Brasil, Rio de Janeiro, Paz e Terra, 1978, 243-262. 
MÉNDEZ, Juan E., O’DONNELL Guillermo y PINHEIRO, Paulo, La (in)efectividad de la ley y la exclusión en América Latina, Buenos Aires, Paidós, 2002

MOTTA, Rodrigo Patto ,"A violência política no Brasil republicano: uma análise das leis e instituições repressivas (1889-1988)", presentado en: III Coloquio Internacional sobre Violencia Polìtica em el Siglo XX, IV Jornadas de Trabajo de la Red de Estudios sobre Represión y Violencia Política (RER) Facultad de Humanidades y Artes, Universidad Nacional de Rosario, 24 al 26 de abril de 2019

PEREYRA, Sebastián, ¿Cuál es el legado del movimiento de derechos humanos? El problema de la impunidad y los reclamos de justicia en los noventa", en SCHUSTER, Federico y otros (comps.), Tomar la palabra. Estudios sobre protesta social y acción colectiva en la Argentina contemporánea, Buenos Aires, Prometeo, 2005.

PERELMAN, Marcela y TUFRÒ, Manuel (2017), Violencia institucional. Tensiones actuales de una categoría política central, Buenos Aires, Centro de Estudios Legales y Sociales, 2017.

PITTALUGA, Roberto, “La memoria según Trelew”, Sociohistórica. Cuadernos del CISH, La Plata, 19, 2018, pp. 81-111

RICOUER, Paul,. La historia, la memoria, el olvido, Buenos Aires, FCE, 2004

SCARPONETTI, Patricia, Violencias, In/seguridades y acceso a los derechos", en: LLOVET Ignacio y SCARPONETTI, Patricia (coords), Estudios sobre condiciones de vida en la Argentina contemporánea, Buenos Aires: CLACSO/PISAC, 2019, pp.15-47.

TISCORNIA, Sofia, "La seguridad ciudadana y la cultura de la violencia", en: Encrucijadas, N5, 1997, pp. 17-29.

TISCORNIA, Sofía y SARRABAYROUSE OLIVEIRA, María José, "Sobre la banalidad del mal, la violencia vernácula y las reconstrucciones de la historia", en Burocracias y violencia Ensayos sobre Antropología Jurídica, en TISCORNIA, Sofía (ed.), Buenos Aires, Antropofagia, 2004, pp.63-74.

VIAL SOLAR, Tomas (editor general), Informe anual sobre Derechos Humanos en Chile, Santiago de Chile: Centro de Derechos Humanos, Facultad de Derecho, Universidad Diego Portales, 2017.

TRAVERSO, Enzo, La violencia nazi. Una genealogía europea, Buenos Aires, Fondo de Cultura Económica, 2003. 
VALDIVIA, Verónica, "Subversión, Coerción y consenso. Violencia estatal en el Chile del Siglo XX" , presentado en: III Coloquio Internacional sobre Violencia Polìtica em el Siglo XX, IV Jornadas de Trabajo de la Red de Estudios sobre Represión y Violencia Política (RER) Facultad de Humanidades y Artes, Universidad Nacional de Rosario, 24 al 26 de abril de 2019.

VILLALTA, Carla, Entregas y secuestros. El rol del Estado en la apropiación de niños. Buenos Aires: Ediciones del Puerto/CELS, 2012.

RECEBIDO EM: 05/09/2019 APROVADO EM: 18/09/2019 